\title{
De la palabra a la imagen: Dark Water, un cuento de fantasmas
}

\section{From the word to the image: \\ Dark Water, a ghost tale}

\author{
JosÉ EdUARDo BAZÁn GUZMÁN \\ Universidad Iberoamericana, Ciudad de México \\ eduard_hp_2@hotmail.com \\ ID ORCID: 0000-0002-3708-2789
}

\begin{abstract}
Resumen: Las películas que están basadas en libros, suelen ser valoradas de acuerdo con su fidelidad respecto a la historia original. Una forma de revalorizar estas películas es analizándolas como una nueva lectura del original. En el caso de la película Dark Water (Honogurai mizu no soko kara) del director japonés Hideo Nakata, a partir de fórmulas narrativas se puede identificar y comprender cuáles son las ganancias que el relato de Koji Suzuki obtuvo en el traslado al cine.
\end{abstract}

Palabras clave: Adaptación fílmica, Cine de terror japonés, Hideo Nakata, Koji Suzuki, Dark Water.

\begin{abstract}
Movies that are based on books are usually valued according to their fidelity to the original story. One way to revalue these films is by analyzing them as a new reading of the original. In the case of the film Dark Water (Honogurai mizu no soko kara) by the Japanese director Hideo Nakata, from narrative formulas it can identify and understand what are the gains that the story of Koji Suzuki, obtained in the transfer to the cinema.
\end{abstract}

Key Words: Film adaptation, Japanese horror cinema, Hideo Nakata, Koji Suzuki, Dark Water. 


\section{José Eduardo Bazán Guzmán}

\section{LA "FIDELIDAD” COMO CRITERIO IMPRODUCTIVO}

El cine, desde sus inicios, ha tenido una estrecha relación con la literatura. Ha tomado clásicos universales como, por ejemplo, El Jorobado de Nuestra Señora o Los Miserables de Víctor Hugo, hasta cuentos cortos para convertirlos en representaciones cinematográficas. A lo largo de su historia conjunta han creado una sólida simbiosis. En la actualidad, las cuestiones mercadológicas han acrecentado los beneficios de esta relación, como cuando semanas después del estreno de un blockbuster, la editorial relanza una edición del libro sobre el que se basó la película, con la imagen de los protagonistas en la cubierta.

Adaptar un texto para un filme siempre es tarea complicada, sobre todo si el libro ha tenido un gran éxito y se espera que la producción cinematográfica lo supere, en cuanto a taquilla se refiere. Pero más importante aún, es que se espera que la película sea "fiel" a la esencia que transmite el libro, a pesar de las precauciones que hemos de tomar con ese concepto, que ha distorsionado en buena medida los estudios sobre las adaptaciones de la literatura al cine (Stam, 2009). Cuando se activa un prejuicio como ese, que pone a la literatura en rango de superioridad sin más, se olvida a menudo que el cine también posee gran capacidad sugestiva cuando se construye a partir de textos literarios. Por ejemplo, Carrie, el libro escrito por Stephen King, narra lo siguiente:

Y, en un impulso ciego y repentino, reunió todo el poder que podía sentir. Algunas de las luces empezaron a echar humo. Hubo un destello deslumbrante en alguna parte cuando un cable eléctrico cayó sobre un charco de agua. Se producían sordos golpes en su mente cuando los cortocircuitos operaban inútilmente. El muchacho que estaba aferrado al pie del micrófono cayó sobre uno de los amplificadores y se produjo un estallido de chispas color morado y luego el empavesado del papel crepé que cruzaba el escenario empezó a arder. Justo bajo los tronos, un cable eléctrico de 220 voltios crepitaba en el suelo. Junto a él, Rhonda Simard, vestida con su traje de gala de tul verde, ejecutaba el espasmódico baile de un títere. Repentinamente, su traje ardió en llamas y ella cayó hacia delante sin dejar de moverse. Quizás ése fue el momento en que Carrie perdió el control. Se apoyó contra las puertas. Su corazón latía frenéticamente, pero su cuerpo estaba helado como un témpano. En su rostro lívido se destacaban dos afiebradas manchas rojas que coloreaban sus mejillas. Su cabeza palpitaba intensamente y había desaparecido todo pensamiento consciente. Se alejó de las puertas tambaleante y las mantuvo cerradas, aunque sin propósito ni plan alguno. En el interior las llamaradas se hacían más brillantes y se dio cuenta borrosamente de que el umbral había sido alcanzado por el fuego (King, 1974: 83).

Esta descripción de lo que sucedió en el baile de graduación de Carrie y que fue el desencadenante para la serie de desastres que ocurrirían, no 
tiene comparación alguna con la impactante escena del filme de Brian de Palma (Carrie, 1976), donde Sissy Spacek, sobre un escenario en llamas, bañada en sangre, con unos exorbitantes ojos llenos de la ira más grande y a través de sus habilidades de telequinesis, cobra venganza contra todos aquellos que la hirieron. Otro ejemplo, siguiendo en la línea de Stephen King, es la formidable actuación de Kathy Bathes en Misery (Rob Reiner, 1990) como esa psicópata obsesionada con el personaje de una novela, y de la que el mismo King refiere que es su adaptación favorita de la larga lista que se ha hecho de sus libros.

Cuando el lector de la novela se imagina lo que King relata, hay innumerables escenarios posibles en su mente, algunos más terroríficos o impactantes que otros. El cine, que no es ajeno, ni mucho menos, a esa capacidad imaginativa, puede, además, potenciar lo sensitivo mediante la tecnología. Anteriormente la vista y el oído eran los sentidos estimulados al asistir a una sala de cine; hoy en día con las recientes salas 4DX, el espectador es capaz de percibir también a través del tacto y el olfato lo que sucede dentro de la película, de manera que la afirmación de Robert Stam cobra mayor vigor: «Las películas implican una respuesta corporal de manera más directa que las novelas» (2009: 18). Por ejemplo, en la película coreana Tren a Busan (Busanhaeng, 2016), hay una escena donde descarrilla uno de los trenes donde los protagonistas tratan de huir del apocalipsis zombie. Con la tecnología 4DX, las butacas de los espectadores se mueven e inclinan simulando los movimientos del descarrilamiento, aunado al intenso chirrido metálico del vagón del tren, a las luces estroboscópicas dentro de la sala y a los golpes en los respaldos de las butacas, como si se tratase de los golpes que los protagonistas reciben en el accidente: aumentan así la respuesta corporal de la que habla Stam.

Al margen ya de este ejemplo extremo, esta respuesta se produce en todos los géneros cinematográficos, pero es muy evidente sobre todo en las películas de terror, cintas que son proyectadas en las salas de cine y donde la audiencia grita por lo que sucede en pantalla, e incluso hay quien abandona la sala por no tolerar lo que está viendo.

Las razones antropológicas de este panorama son muy conocidas (Gubern y Prat, 1979) y no voy a insistir en ellas. Lo cierto es que, a pesar de esta capacidad sugestiva del cine, la opinión generalizada suele decantarse por las novelas en detrimento de sus adaptaciones al cine, sobre todo porque se impone una cierta sensación de pérdida. La novela se ha llegado a considerar como ese original sagrado que debería ser intocable y mucho menos trasvasado a otro medio.

Existen novelas que han sido trasladadas al filme y que han dejado al público satisfecho con la forma como se llevó a cabo la adaptación, alegando que la película es "fiel" a la novela. Esta noción tan peligrosa de 
"fidelidad" radica en el entendido de que a partir de las herramientas que posee el cine, fue posible extraer lo esencial de la novela original y plasmarla en imágenes. Pero, ¿qué partes de la novela son en realidad esenciales para la historia a la hora de integrarlas en el filme y cuáles no? El criterio para hacerlo es totalmente subjetivo, así que pueden hacerse dos o más versiones cinematográficas de una misma novela, con diferentes elementos cada una de ellas y aun así ser versiones supuestamente «fieles”. Por ejemplo, la versión de It (1990) es considerada una versión "fiel" al original de Stephen King de casi 1.000 páginas que es la novela. La versión de 2017 también es así considerada, pero estas dos adaptaciones son muy diferentes entre sí, lo que demuestra la infertilidad de dicho criterio para estudiar un trasvase de la literatura al cine.

Así que, en realidad, las adaptaciones no deberían entenderse de acuerdo con su grado de pretendida "fidelidad" al texto original, sino como nuevas lecturas de la novela, según las razonables reclamaciones del libro fundamental de Robert Stam (2009). Un concepto importante para considerar los filmes como relecturas, es el que propone Genette (1989): la transtextualidad. Existen diversos tipos de transtextualidad, es decir, diversas formas en las que un texto se relaciona con otros. Uno de estos es la hipertextualidad, en la cual un texto llamado hipertexto tiene una relación directa con otro texto llamado hipotexto. En este caso el texto original es un hipotexto, que es la fuente primigenia de la que emana el hipertexto, es decir todos los textos relacionados o basados en el original. La novela es el hipotexto y las sucesivas adaptaciones el hipertexto.

En el cine de terror japonés, existen dos buenos ejemplos. En el año de 1998 llega a las pantallas de cine una película que sembraría el miedo en el público de Japón y que sentaría las bases para el llamado boom del cine de terror japonés. Es Ringu, realizada por Hideo Nakata. Está basada en el libro homónimo de Koji Suzuki, publicado en 1991, el cual rápidamente se convirtió en un best seller. Es decisión del mismo escritor que sea Hideo Nakata quien lleve la batuta de dirigir la versión fílmica de su libro, tras haber visto su trabajo como director en algunos cortometrajes y en su primer largometraje Ghost Actress (1996). Si se analizara la supuesta "fidelidad" de esta cinta con respecto al texto original de Suzuki, entonces podría juzgarse como una mala adaptación debido a los numerosos cambios que presenta, por ejemplo, respecto a los personajes. Pero, si se estudia como un producto que surge de otra visión o lectura de la historia original y que debido al medio en el que se produce, utiliza las herramientas cinematográficas a su favor para contar la historia, entonces el producto es otra interpretación de la misma historia. Para la adaptación del libro de Ringu, Nakata retomará elementos de las tradicionales historias de fantasmas japonesas como la historia de 
Oiwa. El resultado es una cinta que contiene elementos narrativos y audiovisuales decisivos que marcaron el desarrollo de películas posteriores a ella.

El otro ejemplo, en el que voy a detenerme, contiene numerosas similitudes con Ringu. Es Dark Water (Honogurai mizu no soko kara, 2002), película basada en un cuento escrito por Koji Suzuki publicado en 1996 y que también será llevado a la pantalla grande por Hideo Nakata en 2005, siete años después de su éxito con Ringu. Nuevamente, si se analizara el cuento según el criterio de la supuesta "fidelidad", el segundo terminaría fallando a este propósito, pero como producto que surge de una nueva interpretación del texto, el resultado es bien distinto. Vale la pena un análisis más profundo para comprender la riqueza tanto del cuento como de la cinta.

\section{La ADAPTACión de Dark Water (Koji Suzuki, 2002/Hideo NAKATA, 2005)}

Si bien realizar un análisis contraponiendo un cuento y una película suele ser complicado debido a la notable diferencia de medio en el que se encuentran, Zavala propone una serie de fórmulas narrativas que pueden ser aplicables a cualquier producción narrativa:

En la teoría de la adaptación, la utilidad de las fórmulas narrativas consiste en la posibilidad de comparar la naturaleza incoativa y terminativa del texto literario original y el texto fílmico, precisando así la manera como las condiciones de producción cinematográfica contribuyen a preservar o modificar la naturaleza original del material literario (2018: 193).

El número de páginas del cuento (21 en la traducción al español que he empleado), en apariencia, podría ser ideal para la realización de un cortometraje, pero para un largometraje era necesario adicionar elementos: prácticamente escribir una nueva historia basada meramente en los elementos esenciales que transmite el hipotexto, es decir, el original.

\subsection{El suspenso narrativo}

Para analizar las ganancias que presenta la película respecto al cuento original, la primera fórmula narrativa que podemos activar es el suspenso narrativo, que «consiste en que el espectador (o lector) sabe algo que el personaje ignora... (E s, P -s) el Espectador (E), sabe algo (s) que el Personaje (P) no sabe (-s)» (Zavala, 2018: 174-175).

En el cuento, Yoshimi relata un poco acerca de cómo llegó a vivir a ese bloque de departamentos, cómo era la vida con su marido, del que lleva cuatro años separada, y un poco acerca de la historia del edificio. Se 
trata de un complejo de departamentos que debido a la burbuja inmobiliaria japonesa se vio afectado y que solo alberga oficinas durante el día, para vaciarse casi por completo durante la noche, salvo cinco inquilinos. Hasta este punto nada fuera de lo común que pudiera dar a entender al lector que algo extraño está por suceder: al contrario, parece como si el edificio donde viven es una gran oportunidad, ya que lo alquila a un precio muy por debajo de lo normal, y, además, como se utiliza para oficinas, está en muy buen estado. Es hasta el momento en el que Yoshimi y su hija Ikuko deciden subir a la azotea de su edificio, que el descubrimiento de una mochila roja con la imagen estampada de Hello Kitty comienza a despertar la duda en ella. Después de entregarla al conserje para que la exhibiera en el mostrador, esperando que su dueño apareciera, Yoshimi comienza a experimentar cierta obsesión con ella. Es en este punto cuando el lector también se da cuenta de que la mochila tiene una historia detrás y que está a punto de afectar a Yoshimi e Ikuko.

Por su parte, la película es muy distinta: desde el momento en el que Yoshimi e Ikuko llegan al edificio a ver el departamento que van a rentar, el espectador ya puede intuir que no es una buena idea mudarse ahí. Hay algo que no está bien con ese edificio, hay algo maligno en ese lugar. Es totalmente gris, se encuentra en ruinas, abandonado y muy deteriorado por el agua: es un espacio escalofriante. No es el lugar óptimo para vivir ni criar a una pequeña niña. Pero Yoshimi se ve obligada a ello porque se puede observar en escenas anteriores, que está enfrentando un difícil proceso de divorcio y, por tanto, ese departamento parece por el momento su mejor opción. La escena que dará a entender de manera más directa al espectador que en ese edificio hay fantasmas, es la del ascensor. Al llegar al edificio, Yoshimi, Ikuko y el empleado de bienes raíces entran al ascensor; en ese momento, una toma cerrada permite observar cómo una mano pequeña toma la de Yoshimi y ella sonríe pensando que se trata de Ikuko. Acto seguido se abre la puerta y la pequeña sale corriendo dejando desconcertada a su madre, que sigue sosteniendo algo en la mano. Desde su lugar el conserje observa esta escena a través de un monitor, y cuando todos abandonan el elevador, aparece en el monitor la silueta oscura de una niña acompañada de un sonido escalofriante y un acercamiento de la cámara hacia esa sombra. Este es el punto a partir del cual el espectador sabe que hay un fantasma en el edificio y que afectará a la vida de los personajes aunque ellos aún no lo sepan. Los sonidos, las actuaciones, la escenografía, la ambientación y los movimientos de cámara son elementos que permiten comprender esto, porque enfatizan el suspenso.

Cuando el empleado de bienes raíces está mostrando el departamento a Yoshimi se da cuenta de que hay una mancha de humedad en el techo. 
Un sonido estremecedor, parecido al del ascensor, se escucha mientras observa la mancha, relacionando directamente los dos hechos en la película. Un acercamiento de la cámara permite ver su expresión, donde se manifiesta no la preocupación por una simple gotera, sino por algo más oculto. Yoshimi decide mudarse al departamento, y en su primera noche, al observar el techo con cara de extrañeza, encuentra la gotera mientras se escucha leventemente un sonido escalofriante parecido a los anteriores, lo que permite al espectador darse cuenta de que esa filtración de agua traerá problemas insospechados. Si una gotera siempre es un problema molesto en un hogar, lo es más si viene acompañada de una presencia fantasmal.

\subsection{La sorpresa}

La siguiente es la fórmula de la sorpresa: «(N s, E -s), que se lee de esta manera: el Narrador (N), sabe algo (s) que el Espectador (E) no sabe (-s). El espectador puede saber que algo va a ocurrir, pero ignora qué será o cuándo va a ocurrir» (Zavala, 2018: 176).

En el cuento, el lector sospecha que algo va a ocurrir cuando Yoshimi vuelve a subir a la azotea con su hija Ikuko. En el momento en que está por abrir la puerta, la asalta un mal presentimiento y posteriormente encuentra de nuevo la bolsa roja tirada en el mismo lugar. Yoshimi acude de noche a la azotea pensando que Ikuko fue a recoger la bolsa y cuando entra al ascensor siente una presencia, que le reafirma al lector que algo sobrenatural está ocurriendo en ese edificio:

Quizá fuese solo su imaginación, pero incluso le pareció que la temperatura había bajado de repente en aquellos tres metros cuadrados. No estaba sola. Había una presencia en el ascensor. Sentía en el abdomen el aliento de alguien, un aliento como el que se transforma en vapor blanco los días fríos de invierno (Suzuki, 2015: 15).

Después de estas líneas sería lógico que el lector esperara la aparición o presencia de un fantasma o que comenzaran a ocurrir sucesos paranormales, pero como indica la fórmula, no sabe qué será, ni cuándo ocurrirá.

La película, por su parte, muestra una sucesión de pistas que permiten al espectador inferir que algo siniestro está por acontecer. En un primer plano se muestra que la gotera ha crecido. Un acercamiento de la cámara al rostro de Yoshimi muestra que eso ya se está volviendo una preocupación para ella. Luego decide tomar un vaso con agua del grifo y para su sorpresa y espanto, el agua está sucia y contiene un mechón de cabello negro. Mientras observa el vaso, el espectador escucha nuevamente un sonido similar a los que se escucharon en el ascensor y 
cuando observó la gotera. Quiere decir que todos estos elementos están relacionados entre sí y son indicios de algo. Aquí el director retoma elementos de su anterior película Ringu y que no aparecen en el cuento de Suzuki, uno de ellos, el negro cabello de Sadako que es una característica inherente a los fantasmas vengativos femeninos tan bien estudiados por Antonio Míguez Santa Cruz (2016), que permean en las historias de fantasmas japonesas y en la filmografía de terror de la posguerra, de las cuales Nakata se embebió.

Otro de los elementos que Nakata decide integrar de manera más presente en el filme es el agua. El crecimiento de la gotera y su constante flujo es un indicio de que el mal sigue ahí y acecha cada vez más. Durante toda la película hay presencia de agua alrededor de los personajes, pero una de las escenas que mejor lo demuestra es cuando Yoshimi se queda dormida mientras está recostada en una orilla de la cama. El director muestra lo que ella está soñando en una especie de flashback. Sueña con la pequeña Mitsuko caminando bajo la lluvia hacia el edificio en el que ella vive actualmente. Cuando despierta se da cuenta de que Ikuko no está a su lado en la cama, así que corre a buscarla, primero a la azotea y después al departamento que se encuentra en el piso superior al de ella, y donde ha visto una sombra asomada por la puerta. Al entrar, la escena es surrealista: literalmente está lloviendo dentro del departamento. El agua escurre de las paredes y del techo. El lugar es gris, oscuro y frío, y se encuentra inundado. La llave del fregadero está abierta por completo y el agua cae a borbotones. Mientras camina dentro del departamento, una pequeña figura se acerca a ella. Es Ikuko, que camina sonámbula. Cuando Yoshimi la carga, puede ver detrás de ella, sobre la pared, la sombra de Mitsuko en un acercamiento de la cámara, y el espectador vuelve a escuchar el mismo sonido escalofriante de las veces anteriores. Impresionada y sin apenas poder reaccionar, trata de salir del departamento con Ikuko en sus brazos. Al salir y ver un letrero colocado sobre la puerta, comprende que ese es el antiguo departamento donde vivía Mitsuko, la niña que se encuentra perdida. El uso del agua como asociación con los fantasmas es recurrente en la literatura de Suzuki: tanto en Ringu como en Dark Water, los depósitos de agua fungen como una tumba, Sadako en el pozo y Mitsuko en el tanque. Se trata del agua corriente, que simboliza la vida, frente al agua estancada y putrefacta, que se asocia con la muerte:

La ensoñación comienza a veces delante de agua limpia, llena de inmensos reflejos, que murmura con músicas cristalinas. Concluye en el seno de un agua triste y sombría que transmite extraños y fúnebres murmullos (Bachelard, 2003: 77). 
Nakata aprovecha esto para mostrar de manera muy sugerente la aparición fantasmal: la manifestación de Mitsuko está precedida por el agua.

En un momento determinado, después de que Yoshimi llegara corriendo desesperada a recoger a Ikuko a la escuela, hay un diálogo muy interesante. En un plano ligeramente en picado por encima del hombro de Ikuko, se puede ver a Yoshimi con cara de tristeza, pero muy determinada, mientras le dice a su hija: «Puedo enfrentarme a cualquier cosa, mientras estés conmigo». Este diálogo refuerza la idea que venía gestándose desde las primeras escenas: hay un fantasma en el edificio, algo va a ocurrir y la protagonista tendrá que enfrentarse a ello completamente sola.

Yoshimi acude a quejarse de la gotera al conserje, que no le hace mucho caso, ni le da importancia al asunto. Es la primera señal de que tendrá que enfrentarse en solitario a lo que viene. Cuando lleva a su hija Ikuko a su primer día de clase en su nueva escuela, el director le ofrece buena impresión al inicio, pero él y una profesora regañan a un niño de una manera nada adecuada para su edad, lo que sorprende duramente a Yoshimi. Esa es otra señal de que Yoshimi e Ikuko tampoco contarán con el apoyo de la escuela y se encuentran solas frente a lo que viene.

\subsection{Inicio y fin de las narraciones}

Zavala también propone fórmulas para el análisis de la narratología incoativa, para analizar el inicio y el fin de la narración. En este caso el cuento tiene un inicio clásico:

La Fórmula del Inicio Clásico es $[\mathrm{PG}(\mathrm{t}, \mathrm{e}) \rightarrow \mathrm{PP}(\mathrm{t}, \mathrm{e})]$. El Plano General (PG) es una visión panorámica, de conjunto, que permite conocer el contexto donde ocurrirá la historia y quiénes son los personajes que participan en ella. El Primer Plano (PP) es una perspectiva donde se observa un detalle, es decir, algo muy particular que podría no ser percibido con precisión al observar un Plano General (2018: 181).

Suzuki inicia el relato con Yoshimi tomando un vaso con agua y a partir del sabor desagradable comienza a desarrollar todo el contexto general del cuento. Hace cuánto tiempo que Yoshimi e Ikuko llegaron a vivir a ese edificio, dónde está ubicado, qué edad tiene Ikuko, la burbuja inmobiliaria que le permitió alquilar ese departamento a excelente precio..., es decir, la vida desarrollándose con normalidad.

$\mathrm{Al}$ contrario que el cuento, la película tiene un inicio posmoderno:

La Fórmula del Inicio Posmoderno es $\{\mathrm{PM}(\mathrm{i})=\Sigma[\mathrm{C}(\mathrm{i})+\mathrm{M}(\mathrm{i})]\}$, lo cual significa que en el Inicio Posmoderno, PM (i), coexisten $(\Sigma)$ un inicio clásico, C (i), y un inicio moderno, M (i). El inicio posmoderno es al 
mismo tiempo clásico y moderno; cerrado y abierto; contiene rasgos tradicionales y rasgos experimentales; resuelve los enigmas narrativos y al mismo tiempo plantea nuevos enigmas (Zavala, 2018: 188).

El inicio posmoderno lo marca la escena inicial, donde Nakata muestra a la protagonista Yoshimi de niña, observando la lluvia mientras espera a alguien. Se intuye que es a su madre o podría ser a su padre. Un corte posterior a esa escena muestra a la Yoshimi adulta observando absorta la lluvia. Esto permite, en un primer momento, entender la relación que tiene Yoshimi con el agua, pero a la vez plantea la incógnita acerca de su infancia y qué relación podría tener para el desarrollo de la película. El agua le trae recuerdos de abandono por parte de sus padres. Después, surge la parte del inicio clásico que presenta la situación: Yoshimi se está enfrentando a un duro divorcio y está peleando por la custodia de su hija, a partir de lo cual se intuye que este será el desencadenante para la avalancha de sucesos que están por acontecer.

Aunado a esto, Yoshimi se encuentra en búsqueda de trabajo, su vida ha dado un giro de ciento ochenta grados, ahora tiene que compaginar todas sus actividades para poder cuidar a su hija y que no sufra el mismo abandono que ella sufrió, y que Nakata mostró al inicio del filme. Todo esto suma para crear la atmósfera de soledad y desesperación que poco a poco se va apropiando de la protagonista. La actuación de Hitomi Kuroki logra crear empatía con el espectador, que poco a poco va sintiendo la misma desesperación y ansiedad que ella.

En el desenlace del cuento y la película, el tipo de final se invierte respecto al tipo de inicio. El cuento tendrá un final posmoderno, mientras que la película presentará un final clásico:

La Fórmula del Final Posmoderno es $\{\mathrm{PM}(\mathrm{f})=\Sigma[\mathrm{C}(\mathrm{f}), \mathrm{M}(\mathrm{f})]\}$. Esto significa que el Final Posmoderno, PM (f), es la suma $(\boldsymbol{\Sigma})$ de un Final Clásico, C (f) y un Final Moderno, M (f). A su vez, el Final Posmoderno es un Final Simultáneamente Abierto y Cerrado, es decir, PM (f) $=\Sigma[\mathrm{V}(1)$, V (n)], donde hay simultáneamente Una Verdad Única, V (1), y Muchas Verdades Posibles, V (n) (Zavala, 2018: 191).

En el cuento, Yoshimi tiene una epifanía cuando el conserje le muestra el libro de registros del edificio. En ese momento se da cuenta de que la desaparición de Mitsuko sucedió el mismo día que la apertura del tanque de agua para su limpieza. Atando cabos, llega a la conclusión de que el cuerpo de Mitsuko se encuentra dentro del tanque desde hace dos años, de ahí el mal sabor del agua con el que se inicia el desarrollo del cuento. Aunque este final se muestra claro, porque Yoshimi huye del edificio con la certeza de que el cadáver se encuentra ahí, Suzuki nunca lo confirma en 
su narración. Bien podría ser que Yoshimi estuviera equivocada y todo fuera fruto de su imaginación. En realidad, nunca se confirmará: Suzuki deja la duda.

En cambio, la película presenta un final clásico que cierra todas las incógnitas que se desarrollan a lo largo de la historia: «La Fórmula del Final Clásico es: [C (f) $=\mathrm{V}(1)]$. En esta fórmula se establece que el final (f) de carácter Clásico (C) equivale a una única (1) Verdad (F). Por supuesto, se trata de una Verdad Ficcional» (Zavala, 2018: 183).

Yoshimi está segura de que Mitsuko ha regresado de la tumba para llevarse a Ikuko con ella, como eterna compañera de juegos. Cuando la característica mochila roja aparece dentro de la mochila de Ikuko, Yoshimi se la arrebata y en ese momento tiene una revelación. En una especie de trance, observa cómo la mochila cae dentro de un contenedor de agua. Inmediatamente decide subir a la azotea a revisar el tanque. Cuando toca el agua que escurre del tanque, nuevamente tiene una visión: esta vez puede ver a Mitsuko y la forma como subió al tanque de agua para finalmente caer dentro de él. En este punto de la historia se confirma, a diferencia del cuento, dónde se encuentra el cuerpo de Mitsuko.

Después de una serie de sucesos que ponen en peligro la vida de Yoshimi e Ikuko, en los que tienen que huir de la manifestación del agua, viene una de las escenas más impresionantes. Yoshimi corre hacia el ascensor cargando el cuerpo inerte de Ikuko. Dentro del mismo cae agua a borbotones. Yoshimi observa cómo del departamento de Mitsuko emerge la figura de Ikuko, a lo que en un acercamiento de cámara, aterrorizada, se da la vuelta para comprobar que el cuerpo que llevaba cargando, es en realidad el de Mitsuko. Un pequeño cuerpo gris y putrefacto, que la llama mamá, se abalanza sobre ella. En ese momento Yoshimi sabe que debe tomar una decisión: para evitar que Ikuko muera, será ella la que sustituirá para la eternidad a la madre que abandonó a Mitsuko. Con una música triste de fondo que influye en el espectador, Yoshimi le dice, entre llantos, al cuerpo de Mitsuko, mientras lo abraza, que es su madre. Con una simple mirada, Yoshimi se despide de Ikuko, mientras el ascensor cierra sus puertas. Ikuko corre a un piso superior para esperar la apertura del ascensor y que su madre salga de él, pero al abrirse las puertas lo único que se desbordará será una inmensa cantidad de agua putrefacta, agua muerta.

El epílogo cerrará las incógnitas que pudieran haber quedado. En este caso, diez años después, Ikuko llega nuevamente al edificio donde vivió con su mamá, que ahora se encuentra completamente abandonado. Al entrar al departamento, este misteriosamente se conserva intacto. Yoshimi está de pie, esperando a su hija. Esta escena es una de las más conmovedoras del cine de terror moderno. El espectador sabe que 
Yoshimi murió, pero Ikuko platica con ella como si continuara con vida. Ikuko siente una presencia, y por encima de su hombro el espectador puede ver que se trata de Mitsuko. Cuando Ikuko se da la vuelta para observar, su madre ha desaparecido. Ikuko sale del edificio, y mientras se aleja caminando, podemos oír esta reveladora y preciosa frase, con que se cierra el filme: «Mi madre estuvo junto a mí todo este tiempo... protegiéndome».

\section{LA RECOMPOSICIÓN FANTASMAL}

Es interesante observar que Nakata convierte el cuento de Suzuki en una historia de fantasmas, como ya obró con Ringu (Malpartida, 2014: 108). Ninguna de las dos historias muestra a los fantasmas de Sadako ni Mitsuko, pero en las películas Nakata logra configurar una nueva versión de ellas. Investigadores como Berton, que analizan las relaciones entre el cine y las ciencias "de la mente", explican una fuerte relación entre el cine y lo fantasmal. La invisibilidad e inaudibilidad de un fantasma para los vivos requiere de un médium que permita su manifestación. El cine posee las mismas características de invisibilidad e inaudibilidad, y es el cinematógrafo el "médium" a través del cual se hace presente «como una máquina-cinema de captación-proyección del fantasma» (Berton, 2018: 478). El cine, por tanto, es un medio dotado, desde su esencia, para la representación de lo fantasmal. Más allá de las descripciones que Suzuki pudiera haber hecho del fantasma de Mitsuko, lo cierto es que las transparencias, las sombras, la ambientación o el sonido, entre otros factores, permiten representar lo fantasmal de manera muy efectiva.

El cuento de Suzuki contiene los elementos necesarios para crear suspenso en el lector, para sembrar la incógnita al final de su historia. Pero la película de Nakata va más allá. No es una adaptación muy apegada al texto literario, como se mencionó en nuestro punto de partida metodológico, sino una muy interesante manera de recontar la historia que le sirve de base y convertirla en un excelente relato de fantasmas.

\section{BibliogRAFÍA CITADA}

Bachelard, Gaston (2003), El agua y los sueños, México, Fondo de Cultura Económica.

Berton, Mireille (2018), Voir des fantômes, París, Kimé.

Genette, Gérard (1989), Palimpsestos (La literatura en segundo grado), Madrid, Taurus.

Gubern, Román y Joan Prat (1979), La raíces del miedo. Antropología del cine de terror, Barcelona, Tusquets.

KING, Stephen (2012), Carrie, Barcelona, Debolsillo. 
De la palabra a la imagen: Dark Water

MalPartidA, Rafael (2014), Espectros de cine en Japón. Entre la literatura, el cine y las nuevas tecnologías, Gijón, Satori.

Míguez Santa CruZ, Antonio (2016), El fantasma en el cine japonés de posguerra. De rasgo folclórico a icono feminista [Tesis Doctoral], Universidad de Córdoba.

STAm, Robert (2009), Teoría y práctica de la adaptación, México, Universidad Nacional Autónoma de México.

Suzuki, Koji (2015), Dark Water, Gijón, Satori.

Zavala, Lauro (2018), Para analizar cine y literatura, Madrid, El barco ebrio.

Fecha de recepción: 19/07/2019.

Fecha de aceptación: 10/09/2019. 